\title{
Does Voice Therapy Cure All Vocal Fold Nodules?
}

\author{
${ }^{1}$ Baisakhi Bakat, ${ }^{2}$ Abhishek Gupta , ${ }^{3}$ Arunima Roy, ${ }^{4}$ Amitabha Roychoudhury, ${ }^{5}$ Barin Kumar Raychaudhuri
}

\section{ABSTRACT}

Introduction: Vocal nodules are known to be one of the most common benign lesions, commonly situated at the junction of anterior one third and posterior two third of vocal folds. Voice therapy is considered to be the gold standard of treatment of vocal fold nodule.

Objectives: To determine the efficacy of voice therapy in the treatment of vocal fold nodules and to identify any possible reason for failure to voice therapy in managing vocal fold nodules.

Materials and methods: A prospective study, conducted over a period of 6 months. Eighteen adult patients diagnosed with vocal fold nodules at a tertiary care hospital were subjected to 6 weeks of voice therapy. Pre and post therapy subjective (Voice Handicap Index-10) and objective (Rigid fiber optic laryngoscopy) evaluation was done. Patients with no improvement after 6 weeks of voice therapy underwent micro laryngeal surgery. All patients were followed up at 3 months and 6 months.

Results: In majority of patients, objective and subjective voice outcome parameters were significantly improved after voice therapy. Although a few cases showed no significant improvement after therapy, they recovered completely after microlaryngoscopic surgery. It was found that patients who required surgery even after voice therapy had hard nodules.

Keywords: Vocal fold nodule, Voice therapy, Microlaryngoscopic surgery.

How to cite this article: Bakat B, Gupta A, Roy A, Roychoudhury A, Raychaudhuri BK. Does Voice Therapy Cure All Vocal Fold Nodules? Int J Phonosurg Laryngol 2014;4(2):55-59.

\section{Source of support: Nil}

Conflict of interest: None

\section{INTRODUCTION}

Benign vocal fold mucosal disorders, causing varying degrees of dysphonia have serious impact on the personal and professional well being of a person. Vocal fold vibrations produce stress on the vocal fold surfaces during phonation. Maximum mechanical stress occurs at the mid portion of the membranous vocal fold during phonation. Therefore vocal overuse, misuse and abuse lead to excessive stress and trauma in the mid membra-

1,2 Postgraduate Trainee, ${ }^{3}$ Speech and Language Therapist ${ }^{4}$ Professor and Head, ${ }^{5}$ Professor and Honorary Consultant

${ }^{1-5}$ Department of ENT and Head and Neck Surgery, Vivekananda Institute of Medical Sciences, Kolkata, West Bengal, India

Corresponding Author: Amitabha Roychoudhury, Professor and Head, Vivekananda Institute of Medical Sciences, Kolkata West Bengal, India, e-mail: aroychoudhury@yahoo.com nous part of the vocal fold, resulting in wound formation and subsequent tissue remodeling during the healing process of the wound. As a result pathological changes occur in the vocal folds which may lead to formation of vocal nodules, vocal polyps and cysts. ${ }^{1}$

Vocal nodules (Fig. 1) develop on the free edge of the vocal folds as bilateral small swellings, less than $3 \mathrm{~mm}$ in size. They are histologically characterized by thickening of epithelium with a variable degree of underlying inflammation. The exact etiology of vocal nodules is not known but traditionally thought to occur due to vocal abuse or misuse rather than overuse. ${ }^{2}$

According to McGlashan ${ }^{3}$ vocal nodule, also known as singers nodule, is a localized chronic hypertrophic laryngitis, more commonly found in females as compared to males. Patients present with a history of hoarseness and vocal fatigue. ${ }^{4}$

Psychological factors, infections of nose, throat and chest and allergies have been implicated in the etiology of vocal nodules in the past. ${ }^{5-7}$

Laryngopharyngeal reflux is emerging as a probable etiological factor of vocal fold nodule in addition to vocal abuse and misuse. ${ }^{8-10}$

Diagnosis is clinched by eliciting a proper history from the patient including duration of voice abuse per day, status of hydration, profession and personal habits like smoking or alcohol intake. Though indirect laryngoscopy can detect vocal fold nodules in most of the cases, the diagnosis is confirmed by either rigid or flexible laryngoscopy, with or without stroboscopy. Stroboscopy is useful to distinguish between vocal nodule and vocal fold $^{\text {cyst. }}{ }^{11}$

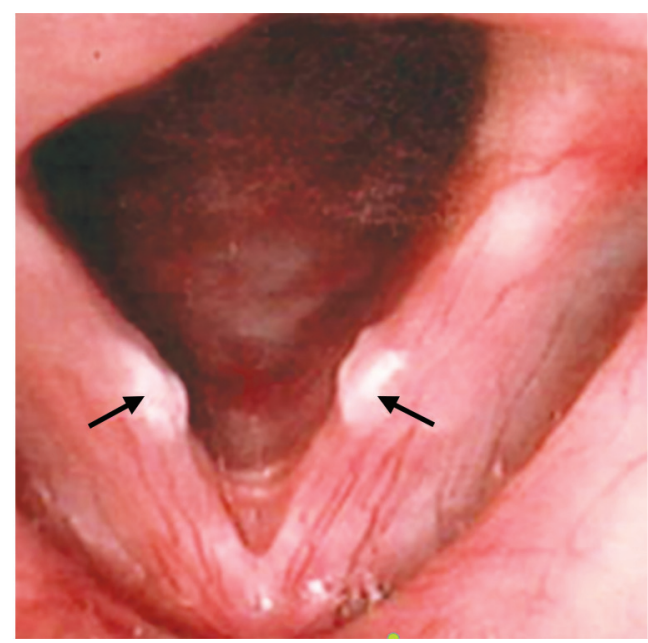

Fig. 1: Vocal fold nodules 
Table 1: The voice handicap index-10 questionnaire

\begin{tabular}{|c|c|c|c|c|c|}
\hline SI. no. & 0 & 1 & 2 & 3 & 4 \\
\hline $\mathrm{P} 1$ & My voice makes it difficult for people to hear me & & & & \\
\hline P2 & I run out of air when I talk & & & & \\
\hline F3 & People have difficulty in understanding me in a noisy room & & & & \\
\hline F4 & The sound of my voice varies throughout the day & & & & \\
\hline F6 & $\begin{array}{l}\text { My family has difficulty hearing me when I call them } \\
\text { throughout the house }\end{array}$ & & & & \\
\hline E7 & I use the phone less often than I would like to & & & & \\
\hline F8 & I am tense when talking to others because of my voice & & & & \\
\hline E9 & People seem irritated with my voice & & & & \\
\hline P10 & People ask 'what is wrong with your voice?' & & & & \\
\hline
\end{tabular}

Min. score: 0; Max. score: 40

Vocal fold nodules can be treated with voice therapy (e.g. voice re-training, rest or hygiene advice) and adjunctive medical or pharmacological treatment of underlying laryngopharyngeal reflux. Cases refractory to voice therapy are usually amenable to phonomicrosurgery. ${ }^{12}$ But there is a need for high-quality randomized controlled trials to evaluate the effectiveness of surgical and nonsurgical treatment of vocal cord nodules. ${ }^{13}$

Voice therapy is the treatment of choice in which patients are re-educated for proper use of voice by suitable training programs that motivates them to change faulty vocal habits and eliminate vocal misuse and abuse. Unless the incorrect vocal habits are addressed there is a high possibility of recurrence. Voice therapy from a speech language therapist includes teaching good vocal hygiene, reducing or stopping vocal abusive behaviors and direct voice treatment in the form of specific maneuvers and exercises to alter the pitch, loudness or breath support for good voicing. ${ }^{14}$

Thus, mainstay for managing vocal fold nodules remains voice therapy and vocal hygiene, which encompases lifestyle modification, treatment of reflux, alteration of vocal behavior and providing guidance for vocal care.

In spite of compliant voice therapy, some patients eventually need phonomicrosurgery for the treatment of vocal nodules. Hence, we undertook this study to find out the efficacy of voice therapy in treating vocal nodules and also to look for reasons behind failure of treatment, if any.

\section{MATERIALS AND METHODS}

A prospective study was undertaken, over a period of 6 months on 18 adult patients. All these patients attending the OPD of ENT and Head Neck Surgery, Vivekananda Institute of Medical Sciences, a tertiary care hospital, were diagnosed to have vocal fold nodules.

\section{Inclusion Criteria}

Adult patients having a laryngoscopically confirmed diagnosis of vocal fold nodule.

\section{Exclusion Criteria}

Any other associated vocal fold pathology.

A detailed history was taken in a specially designed voice clinic Proforma which included duration of complaints, history of vocal abuse or overuse, and if yes how many hours per day, status of hydration, history of hyperacidity, addictions, etc. the profession of the patient was noted including number of hours of professional talking. This was followed by generalized ENT examination including indirect laryngoscopy.

Subjective evaluation was performed by using Voice handicap Index-10 Questionnaire (VHI-10), filled in by the patients at diagnosis, 6 weeks and 6 months (Table 1).

Objective evaluation was based on rigid fiber optic laryngoscopy (FOL) with a $70^{\circ}$ endoscope, performed in all 18 patients. In FOL, nature of the lesion, glottic closure pattern and look of the lesion whether hard or soft was noted.

All patients were subjected to voice therapy for 6 weeks. At the end of 6 weeks, VHI-10 and FOL were performed to check for responses to voice therapy. Patients who showed no improvement after 6 weeks of therapy, either subjectively or objectively, were subjected to surgery for excision of the vocal fold nodule. Microlaryngoscopic cold steel surgery was done in all cases taking care not to disrupt the deeper layer of lamina propria. Voice therapy was continued for 6 weeks following surgery. All patients were advised to continue vocal hygiene for 6 months following surgery. A follow-up was done at 3 months and again at 6 months when subjective and objective findings were noted.

\section{RESULTS}

Of the 18 patients studied, $14(77.78 \%)$ were females and $4(22.22 \%)$ were males. The mean age was 31.56 years.

Mean VHI score of 18 patients at diagnosis was 15.61 (Fig. 2). Fifteen out of 18 (83.33\%) patients showed significant subjective improvement after 6 weeks of 


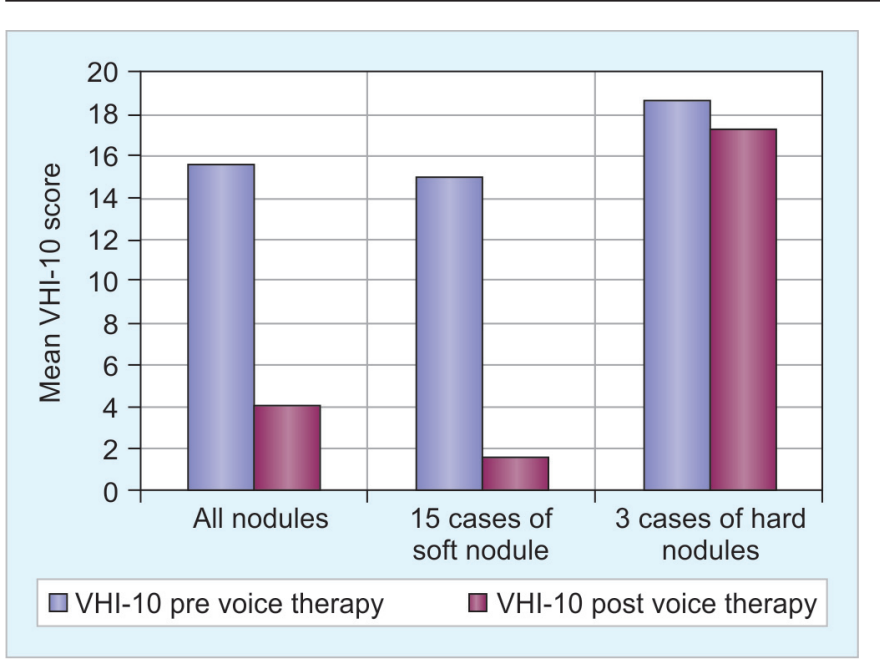

Fig. 2: Subjective evaluation at the end of 6 weeks

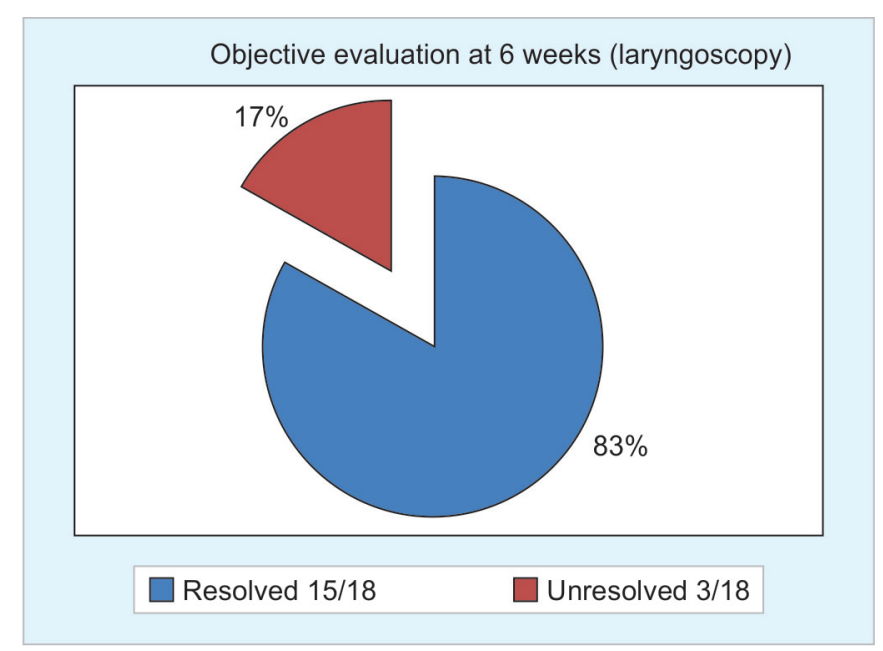

Fig. 3: Objective evaluation at the end of 6 weeks

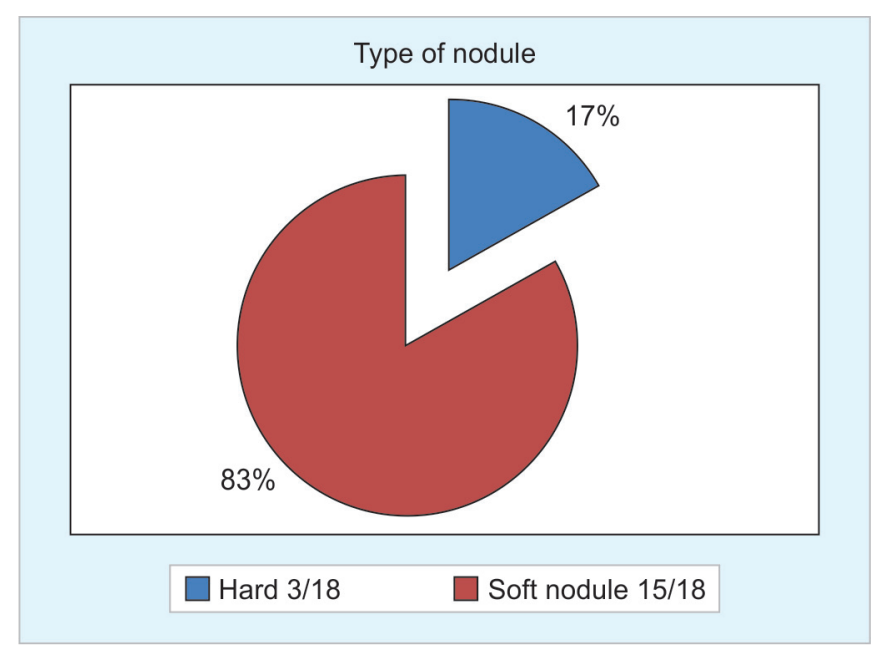

Fig. 4: Number of hard and soft nodules

voice therapy with a mean VHI reduced from 15.61 to 4.1. However, 3 patients (16.67\%) did not show any significant improvement of their symptoms with pretherapy and post-therapy mean VHI being 18.66 and 17.33 respectively. VHI of 15 patients with soft nodules reduced significantly from 15 to 1.46 .
On laryngoscopic evaluation, after 6 weeks of voice therapy, 15 out of 18 patients $(83.33 \%)$ showed resolution of nodule and rest $3(16.67 \%)$ patients had persistent nodule (Fig. 3). On further analysis, it was noted that these 3 patients $(16.67 \%)$ who were refractory to voice therapy were diagnosed to have hard nodules at initial visit, whereas 15 patients (83.33\%) who responded to voice therapy had soft nodules (Fig. 4).

Three patients with hard nodules were subjected to microlaryngoscopic excision of vocal nodule. They were also continued with postoperative voice therapy for 6 weeks. All 18 patients were advised to practice vocal hygiene upto the end point of the study, i.e. 6 months.

At 6 months follow-up, 1 patient (5.5\%) out of 18 patients was found to have recurrence of nodule and this patient belonged to the hard nodule group.

\section{DISCUSSION}

Benign lesions of the vocal fold are common cause for hoarseness. More thorough understanding of these benign lesions has been the goal of laryngologists and voice scientists over the last several decades, since Hirano's description of the complex layered microanatomy of the human vocal fold.

Ratio of prevalence of nodules in male and female before puberty is seen to be around 3:1, while after puberty it is 1:3. ${ }^{15}$ Among women most often seen around aged 20 to 50 years. ${ }^{16-18}$ In our study, $77.78 \%$ patients were females and the mean age of these females was 30.14 years.

Vocal fold nodules are commonly believed to occur as the result of phonotrauma which includes vocal abuse and vocal misuse. Vocal abuse refers to vocal behaviors that lead to trauma of the vocal fold microstructure. Excessive and prolonged talking with excessive loudness, use of inappropriate pitch, excessive cough, and throat clearing are some of these vocally abusive behaviors. All patients in our series had definite history of vocal abuse.

Vocal misuse is an inefficient method of voice production due to inappropriate laryngeal tension and or poor respiratory drive. This often leads to vocal fatigue and odynophonia. Long-term misuse along with abuse leads to changes in microarchitecture of vocal folds. ${ }^{19}$

Even anatomical considerations like anterior web and short membranous vocal folds are said to predispose to develop vocal fold nodule.

Gray et $\mathrm{al}^{20}$ gave a detailed description of 'basement membrane zone' which anchors the epidermis to the underlying superficial layer of lamina propria. In superficial layer of lamina propria collagen type III and collagen type VII interwine and fixates basement membrane zone to superficial layer of lamina propria. Excessive 
shear leads to disruption of basement membrane zone and development of infiltrates in this zone. ${ }^{21}$ In some individuals basement membrane zone is excessively widened and have less amount of collagen fibers predisposing them to excessive trauma during phonation. ${ }^{22}$

Nodules are bilateral swelling with a classic location at the junction of the anterior and middle third of the vocal fold (i.e. the midpoint of the membranous vocal fold). This region is said to be the 'striking zone', being most active segment during phonation. ${ }^{23}$ This is the site of maximal aerodynamic and muscular forces and also has rich reticular vascular network (venules) on the lower surface of the vocal fold free edge.

Objective assessment of vocal folds can be done using fiberoptic laryngoscopy with or without stroboscopy, on other hand subjective assessment can be done by using various quality of life related questionnaire such as $\mathrm{VHI},{ }^{24}$ VHI- $10,{ }^{25}$ VoiSS (Voice symptom scale), ${ }^{26}$ V-RQOL ${ }^{27}$ (voice related quality of life) to explore the impact of voice disorder on their life. It can also be used for measuring the outcome for estimating the effectiveness of intervention. VHI-10 which has been adapted from a 30 point scale. $\mathrm{VHI}$ is an easy, practical clinical and research tool with strong reliability and validity. ${ }^{28}$ In our study at the end of 6 weeks mean VHI-10 scores were seen to reduce significantly from 15.61 to 4.1 . However, in 3 patients it did not improve satisfactorily, i.e. from 18.66 to 17.33 who were found to have hard nodule.

Voice therapy is the primary recommended treatment for vocal fold nodules. ${ }^{29}$ Attention to correct the underlying causative factors, largely through voice therapy and education, plays an integral role in treatment. Education regarding proper vocal hygiene and hydration and avoidance of vocal abuse, misuse, and overuse is the necessary baseline. ${ }^{30}$ Inhaled irritants such as tobacco and toxic chemicals should also be avoided. Gastroesophageal reflux should be controlled. Patients should be guided regarding proper fluid intake, and medications that have drying potential should be minimized to optimize laryngeal hydration. ${ }^{31}$ Apart from vocal hygiene, voice therapy consist of some voice rehabilitation exercises targeting specific faulty vocal behaviors that contribute to dysphonia which is individualized according to patients need. When performed by a speech language pathologist (SLP) in a compliant patient, voice therapy is highly effective in helping most patients with vocal fold nodule. ${ }^{32}$ Out of 18 patients studied, 15 (83.33\%) were cured after 6 weeks of voice therapy well corroborating with the study by Mc Crory ${ }^{33}$ in which $76 \%$ patient were cured only by voice therapy.

Several authors have published papers relating to phonosurgical techniques for removal of benign lesions. Although, the surgical removal of nodules is relatively uncommon, recommendations for such a procedure include minimal normal tissue disruption. Given that surgery for vocal fold nodules is rare and fewer than 5\% of cases and it should be considered only after a thorough nonsurgical treatment regimen is unsuccessful. ${ }^{34}$ In our study, 3 cases out of 18 (16.67\%) even after 6 weeks of voice therapy required surgery. However, statistical analysis was not possible in the series, as it was conducted in a limited number of patients.

Also known as 'calluses of vocal fold', nodules basically are of two types depending upon duration and laryngoscopic appearance: soft or young nodule and hard or old nodule. Soft nodules are acute nodules and are usually translucent, soft and pliable compared to hard or chronic nodules that are firm whitish and thick. ${ }^{35,36}$ All 3 patients who underwent surgery in our study were found to have hard nodules.

At the end point of our study at 6 months, 1 patient $(5 \%)$ had recurrence of nodule. The fact that this patient had hard nodule and is a voice therapy failure, may suggest that 'hard' and more robust nodules may have a tendency to recur. Pre-existing anatomical variants predisposing to excessive shearing force, genetically determined changes in vocal fold microanatomy may also account for recurrence.

\section{CONCLUSION}

It is evident from the present study that majority of soft vocal fold nodules are amenable to voice therapy, whereas hard variety are resistant to therapy. However, hard nodules tend to resolve after phonomicrosurgery, provided postoperative voice therapy is given.

In our opinion, vocal fold nodule should be categorized into soft and hard type at the time of first diagnosis, so the hard type should be surgically treated with supportive pre- and postoperative voice therapy. It will also be useful to develop some validated diagnostic criteria of soft and hard vocal fold nodule. This will enable the clinician to optimize the treatment for vocal fold nodule right from the day of first diagnosis.

\section{REFERENCES}

1. Ju TH, Jung KY, Kwon SY, Woo JS, Cho, Park MW, et al. Effect of voice therapy after phonomicrosurgery for vocal polyps: a prospective, historically controlled, clinical study. J Laryngol Otol 2013 Apr;127(12):1156-1159.

2. Chalabreysee L, Perouse R, Cornut G, Bouchayer M, Loise R. Anatomie et anatamopathologie des lesions benignes des cordes vocalis. Revue Laryngologie Otology Rhinologie 1999;120: 275-280.

3. McGlashan J. Disorders of the voice. In: John Hibbert. Scott Brown's Otolaryngology, Head and neck Surgery. London: Hodder Arnold 2008;2:2198. 
4. Roychoudhuri BK, Inflamations of the larynx. In: Roychoudhuri BK, editor. Synopsis of Otorhinolaryngology. India: CBS publishers and distributers Pvt Ltd; 2013. p. 270.

5. Mcmurray JS. Medical and surgical treatment of pediatric dysphonia. Otolaryngologic clinics of North America 2000; 33(5):1111-1126.

6. Carr MM, Nguyen A, Poje C, Pizzuto M, Nagy M, Brodsky L. Correlation of findings on direct laryngoscopy and bronchoscopy with presence of extraoesophageal reflux disease. Laryngoscope 2000;110(9):1560-1562.

7. Kalach N, Gumpert L, Contencin P, Dupont C. Dual-probe pH monitoring for the assessment of gastroesophageal reflux in the course of chronic hoarseness in children. Turkish J Pediat 2000;42(3):186-191.

8. Kuhn J, Toohill RJ, Uluaip S O, Kulpa J, Hofmann C, Arndorfer $\mathrm{R}$, et al. Laryngopharyngeal reflux: events in patients with vocal cord nodules. Laryngoscope 1998;108(8 pt 1):1146-1149.

9. Toohill RJ, Kuhn JC. Role of refluxed acid in pathogenesis of laryngeal disorders. Am J Med 1997;103(Suppl 5A):S100-106.

10. Uluaip S, Toohill RJ, Massey B, Arndorfer RC, Hogan WJ, Shaker R. Esophagopharyngeal distribution of refluxed gastric acid in patients with vocal cord nodule and chronic sinusitis: Gastroenterology 1998;114:A315.

11. Hirano M, Bless DM. Videostroboscopic examination of the larynx. London: Whurr Publishers Ltd, 1993.

12. Benninger MS, Jacobson B. Vocal nodules, microwebs and surgery. J Voice 1995;9(3):326-331.

13. Pedersen $M$, McGlashan J. Surgical versus nonsurgical interventions for vocal cord nodules. Cochrane Database of Systematic Reviews 2012, Issue 6. Art. No.: CD001934.

14. Vocal cord nodules and polyps. Available at: http://www. asha.org/public/speech/disorders/NodulesPolyps. Accessed on Nov. 10th, 2014.

15. Kleinsasser O. Microlaryngoscopy and endolaryngeal microsurgery: technique and typical findings. In: Kleinsasser O. Philadelphia: Hanley and Belfus 1990. p. 42-43.

16. El Uali Abeida M, Fernández Liesa R, Vallés Varela H, García Campayo J, Rueda Gormedino P, Ortiz García A. Study of the influence of psychological factors in the etiology of vocal nodules in women. J Voice 2013;27(1):127.

17. Cipriani NA, Martin DE, Corey JP, Portugal L, Caballero N, Lester $\mathrm{R}$, et al. The clinicopathologic spectrum of benign mass lesions of the vocal fold due to vocal abuse. Int J Surg Pathol 2011 Oct;19(5):583-587.

18. Yamasaki R, Behlau M, Brasil Ode O, Yamashita H. MRI anatomical and morphological differences in the vocal tract between dysphonic and normal adult women. J Voice 2011 Nov;25(6):743-750.
19. Courey MS, Postma GN, Osoff RH. The professional voice. In: Richardson MA, Flint PW. Cummings otolaryngology head and neck surgery. Philadelphia: Mosby; 2010;1:5:p. 871.

20. Gray SD, Hirano M, Sato KM. Molecular and cellular structure of vocal fold tissue. In: Titze I Red Vocal fold physiology. San deigo. Singular publishing group, 1993.

21. Dikkers FG, Hulstaert CE, Oosterbaan JA, et al. Ultrastructural changes of Basement membrane zone in benign lesions of the vocal folds. Acta Otolaryngol (Stockh) 1993;113(1):98-101.

22. Gray SD. Cellular physiology of the vocal folds. The otolaryngologic clinics of north America 2000 Aug;33(4):684.

23. Hochman I, Sataloff RT, Hillman RE, Zeitels SM. Ectasias and varices of the vocal fold: Clearing the striking zone. Ann Otol Rhinol Laryngol 1999;108(1):10-16.

24. Jacobson BH, Jacobson A, Grywalsky, et al. The voice handicap index (VHI): development and validation. American Journal of Speech Language Pathology 1997;6(3):66-70.

25. Rosen CA, Lee AS, Osborn J, et al. Development and validation of the voice handicap index-10. Laryngoscope 2004 Sep;114(9): 1549-1556.

26. Deary IJ, Wilson JA, Carding PN, Mackenzie K. Voi SS: a patient derived voice symptom scale. J Psychosom Res 2003 May;54(5):483-489.

27. Hogikyan ND, Selhuraman G. Validation of an instrument to measure quality of life. J Voice 1999;13(4):557-559.

28. Rosen CA, Lee AS, Osborne J, Zullo T, Murry T. Development and validation of the voice handicap index-10. Laryngoscope 2004 Sep;114(9):1549-1556.

29. Blood GW, Blood IM, Bennett S, Simpson KC, Susman EJ. Subjective anxiety measurements and cortisol responses in adults who stutter. J Speech and Hearing Res 1994;37(1): 69-82.

30. Wang CT, Liao LJ, Lai MS, Cheng PW. Comparison of benign lesion regression following vocal fold steroid injection and vocal hygiene education. Laryngoscope 2014;124(2):510-515.

31. Voice therapy. Available at: http://emedicine.medscape.com/ article/866712-overview\#a30. Accessed on 10th Nov, 2014.

32. Garcia RT, Garcia RA, Diaz RT, Canizo FRA. The outcome of hydration in functional dysphonia. An Otorrinolaringol Ibero Am 2002;29(4):377-391.

33. Mc Crory. Voice therapy outcomes in vocal fold nodules: a retrospective audit. Int J Language Communication Disorder 2001;36 Suppl:19-24.

34. Jensen JB, Rasmussen N. Phonosurgery of vocal fold polyps, cysts and nodules is beneficial. Dan Med J Feb 2013;60(2):A 4577.

35. Sataloff RT, Spiegel JR, Carroll LM, Schiebel BR, Darby KS, Rulnick R. Strobovideolaryngoscopy in professional voice users: results and clinical value. J Voice 1988;1(4):359-364.

36. Sataloff RT, Spiegel JR, Hawkshaw MJ. Strobovideolaryngoscopy: results and clinical value. Ann Otorhinol Laryngol 1991 Sep;100(9 pt 1):725-727. 